Original Article

\title{
Client Satisfaction among the clients attending tertiary care centers in Mangalore, South India
}

\author{
Usha Rani S.P. ${ }^{1}$, Rashmi Kundapur ${ }^{2}$, Anusha Rashmi ${ }^{3}$, Harsha Acharya ${ }^{4}$ \\ ${ }^{1}$ Assistant Professor, Department of Community M edicine, Sapthagiri Institute of Medical Sciences and Research centre, \\ Bangalore, 'Professor, Department of Community Medicine ,K.S. Hegde Medical Academy, Deralakatte, Mangalore, \\ ${ }^{3}$ Assistant Professor, Department of Community Medicine, A. J. Institute of Health sciences and Research, Mangalore, \\ ${ }^{4}$ Post-graduate, Department of Paediatric Surgery, Kasturba M edical College, M anipal.
}

*Corresponding Author : Usha Rani S.P., \#29,3rd main, G..K.V.KLayout, Allalsandra, Yelahanka, Bangalore- 560065 Mobile: +91 99806 79620, E-mail : ushaspadmanabh@gmail.com.

$\begin{array}{ll}\text { Received } & : 28.07 .2017 \\ \text { Review Completed } & : 20.08 .2017 \\ \text { Accepted } & : 21.08 .2017\end{array}$

Keywords : Client satisfaction, Healthcare, Teaching hospital, waiting time

\begin{tabular}{|c|}
\hline Access this article online \\
\hline Quick Response Code \\
\hline
\end{tabular}

\begin{abstract}
:
Background: Provision of services in line with the wishes and needs of patients is central to a human health care system. The hospital markethastoday as changed from a seller's market to a buyer's market and there is a need to improve the quality in the health care delivery. Client satisfaction is a key determinant of quality of care provided in health care centers.
\end{abstract}

Objectives: To determine the client satisfaction among the patients attending tertiary care centers in Mangalore.

\begin{abstract}
Materials and Methodology: The study was a cross sectional study which was conducted among the clients attending five teaching hospitals in M angalore. With $60 \%$ of client satisfaction obtained in our pilot study, the sample size was 384 and adding 20\% for dropouts the total sample size came up to 462.The clients were selected randomly from each hospital. A pretested Proforma wasused outside the hospital with strict confidentiality.
\end{abstract}

Results: In our study we found that, $87.6 \%$ of the clients felt that the clinic hours at health facility were adequate, $79.3 \%$ felt health care was easily accessible, $89.2 \%$ were happy with hygiene and comfort of waiting area. Average waiting time was 116 mins. Only $45.4 \%$ could meet the same service provider in follow up visit and only $51.5 \%$ availed similar services as in the first visit in the follow up. Satisfaction with provider's skill and ability was seen in $82.5 \%$ of the clients. Only $69.2 \%$ of the clients were satisfied with the cost of services available.

Conclusion: Our study revealed that waiting time was a major concern for the client's satisfaction.

\section{Introduction}

The hospitals have evolved from being an isolated sanatorium to a place with five star facilities. Clients coming to the hospital not only expect the world class treatment but also other facilities to make their stay comfortable in the hospital. ${ }^{1}$. Client satisfaction can be defined as fulfillment or meeting of expectations of a person from a service or a product in relation to his or her expectations. If the performance of a service or a product falls short of expectations, customer is dissatisfied and if it matches the expectations, the customer is satisfied. To achieve patient satisfaction the hospital as to develop itself technologically as well as become more service oriented. It is essential for a hospital to reach out to its clients (Patients) if it wants to survive the competition. This can be achieved only by building a bridge of trust between the hospital and the community so that the community can cross over to the hospital. This results in high patient loyalty which is what every hospital is looking at to cut the competition ${ }^{2}$. M easuring client or patient satisfaction has become an integral part of hospital or clinic management strategies across the globe. The quality assurance and accreditation process in most countries requires that the satisfaction of clients be measured on a regular basis. Patient's opinion on care and treatment they have received forms important steps towards improving the quality of 
care.

Donabadian, arguably the leading theorist in the area of quality assurance has emphasized that client satisfaction is of fundamental importance as a measure of the quality of care because it gives information on the providers success at meeting those client values and expectations which are matters on which the client is the ultimate authority ${ }^{3.4}$. In the prior years when hospitals were symbols of humanitarian efforts for the community welfare, accountability for performance was of a little concern. Today however, people are increasingly concerned about the hospitals performance because -1) Hospitals use an increasing proportion of scarce community resources. 2) There are increasing questions about quality and effectiveness ${ }^{4}$. Hence this study aimed to determine the client satisfaction among the patients attending teaching hospitals in Mangalore.

\section{Materials and Methods}

A cross-sectional study was done in the tertiary health care centers of Mangalore during the month of June 2014 and August 2014. Mangalore has seven Private medical colleges attached to the teaching hospitals. This study was carried out among the clients attending these five teaching hospitals we excluded two of the hospitals as it was very new at the time of study and did not have much patient load. A sample size of 384 was determined expecting a satisfaction of $60 \%$ which was seen in the pilot study. The formula of $\mathbf{n}=\mathbf{4} \mathbf{p q} / \mathbf{r} \mathbf{2}$ was used with $\mathrm{p}$ ( prevalence) taken as $60 \%, q=100-p$ and $r$ is the allowable error being $5 \%$. Adding 20\% for the drop outs the total desired sample size was 462 . So as a whole around 92 patients were interviewed in each teaching hospital. The clients were selected randomly from each hospital and it was seen that there was almost equal representation from the departments of M edicine, Surgery, Pediatrics, Obstetrics and Gynecology, Orthopedics, Ophthalmology, ENT and Super-Specialty with 12-13 participants from each department. The interview of all the clients was done outside the compound of the teaching hospital so that there would be no bias in answering the questions.
Complete anonymity about the clients were maintained and ensured so that there was no bias in answering for the clients. A written informed consent was taken from the clients before the initiation of the study. A pre- tested Proforma was prepared involving the time of reaching the health facility, time of waiting and the satisfaction about the health facility, instruments used and the Provider with his / her nature and skills was prepared. Descriptive statistics was used to analyze the data using SPSS version 16. Ethical clearance was obtained from the institutional ethical committee.

\section{Results}

We could find that, $87.6 \%$ of the clients felt that the clinic hours at the health facility were adequate, 3.3\% felt it wasn't enough and there was a need to increase. Average duration taken by the clients to reach the health facility was 120 mins, $79.3 \%$ of them felt that the health care was easily accessible and $19.8 \%$ felt that it was not assessable, $71.9 \%$ of the clients felt waiting time was reasonable and $25.6 \%$ thought it was too long. Average waiting time was 116 mins. Among them $75.8 \%$ believed that follow up was within the reasonable period and $22.5 \%$ said it was not, $73.3 \%$ felt time given by the provider was satisfactory and $24.2 \%$ felt time given by provider was unsatisfactory. Among the clients $89.2 \%$ were happy with hygiene and comfort of waiting area and $88.3 \%$ felt hygiene and comfort of examination room was good.(Table.1)

On the availability of health services for all causes of one's problem were asked , $60.8 \%$ was happy in the hospital they visited and $22.5 \%$ weren't sure to answer the question and $16.7 \%$ felt the health service was insufficient, $70.8 \%$ felt instruments used in the health services were in satisfactory condition and $16.7 \%$ said it was unsatisfactory. Only $45.8 \%$ were able to meet the same health provider in their follow up visits also, only $51.5 \%$ of them availed similar services as in their first visit in follow up, $88.3 \%$ of the clients were happy with the respect and courtesy given by the provider and felt that there was a two way communications, while $7.5 \%$ weren't sure of the same but $4.2 \%$ felt surely not about courtesy and two way 
communication and $87.5 \%$ of the patients were satisfied with the privacy and $86.7 \%$ felt that there was adequate confidentiality.

Satisfaction with provider's skill and ability was seen in $82.5 \%$ of the clients, $6.7 \%$ were not satisfied but $10.8 \%$ said they didn't know. Information about the illness was given only to $72.5 \%$ of the clients. Only $69.2 \%$ of the clients were satisfied with the cost of services available and $79.2 \%$ felt the health services provided was reasonably good and $83.3 \%$ of clients were ready to recommend the health services they utilized to others (Table.2).

Table 2 : Distribution as per Client's opinion on services provided in the health care centre:

\begin{tabular}{|c|c|c|c|c|c|}
\hline SI. & Opinion on & Satisfied & Unsatisfied & Unaware & \begin{tabular}{|l} 
Total \\
\end{tabular} \\
\hline no & & N (\%) & N (\%) & N (\%) & \\
\hline 1. & $\begin{array}{l}\text { Availability of } \\
\text { health services }\end{array}$ & $281(60.8 \%)$ & $77(16.7 \%)$ & $\begin{array}{c}104 \\
(22.5 \%)\end{array}$ & \\
\hline 2. & $\begin{array}{l}\text { Quality of } \\
\text { Instruments used }\end{array}$ & $327(70.8 \%)$ & 77(16.7\%) & $58(12.5 \%)$ & \\
\hline 3. & $\begin{array}{l}\text { Consultation with } \\
\text { same health } \\
\text { provider in } \\
\text { follow up }\end{array}$ & $212(45.8 \%)$ & $250(54.2 \%)$ & 0 (Nil) & \\
\hline 4. & $\begin{array}{l}\text { Communication } \\
\text { skills }\end{array}$ & $408(88.3 \%)$ & $19(4.2 \%)$ & $35(7.5 \%)$ & \\
\hline 5. & Privacy & $404(87.5 \%)$ & $58(12.5 \%)$ & 0 (Nil) & \\
\hline 6. & Confidentiality & $401(86.7 \%)$ & $61(13.3 \%)$ & 0 (Nil) & \\
\hline 7. & $\begin{array}{l}\text { Health provider's } \\
\text { skill }\end{array}$ & $381(82.5 \%)$ & $31(6.7 \%)$ & $\begin{array}{c}50 \\
(10.8 \%)\end{array}$ & \\
\hline 8. & $\begin{array}{l}\text { Disclosure and } \\
\text { Information of } \\
\text { illness }\end{array}$ & $335(72.5 \%)$ & $127(27.5 \%)$ & $0(\mathrm{Nil})$ & \\
\hline 9. & $\begin{array}{l}\text { Cost of the } \\
\text { services }\end{array}$ & $320(69.2 \%)$ & $142(30.8 \%)$ & o(Nil) & \\
\hline 10. & $\begin{array}{l}\text { Quality of health } \\
\text { services }\end{array}$ & $366(79.2 \%)$ & $96(20.8 \%)$ & o(Nil) & \\
\hline & Total=N (\%) & & & & $\begin{array}{c}462 \\
(100 \%)\end{array}$ \\
\hline
\end{tabular}

\section{Discussion}

An increased emphasis on client satisfaction is driven by the perceived need for the democratization of Primary health care. It is useful in assessing consultations and patterns of communications. Patients satisfaction is considered as one of the most important and desired outcomes of the health care services. Efficacy of medical treatment is enhanced by greater patient satisfaction. It
Table 1 : Distribution as per the client's opinion on heath care centre

\begin{tabular}{|c|l|c|c|c|c|}
\hline $\begin{array}{c}\text { Sl. } \\
\text { no }\end{array}$ & Opinion on & $\begin{array}{c}\text { Satisfied } \\
\mathbf{N}(\%)\end{array}$ & $\begin{array}{c}\text { Unsatisfied } \\
\text { N (\%) }\end{array}$ & $\begin{array}{c}\text { Unaware } \\
\text { N (\%) }\end{array}$ & Total \\
\hline 1. & Clinic hours & $405(87.6 \%)$ & $15(3.3 \%)$ & $42(9.1 \%)$ & \\
\hline 2. & $\begin{array}{l}\text { Accessibility of } \\
\text { health care }\end{array}$ & $66(79.3 \%)$ & $92(19.8 \%)$ & $4(0.9 \%)$ & \\
\hline 3. & $\begin{array}{l}\text { Waiting time } \\
\text { for consultation }\end{array}$ & $332(71.9 \%)$ & $118(25.6 \%)$ & $12(2.5 \%)$ & \\
\hline 4. & Follow up & $350(75.8 \%)$ & $104(22.5 \%)$ & $8(1.7 \%)$ & \\
\hline 5. & $\begin{array}{l}\text { Hygiene and } \\
\text { comfort in } \\
\text { waiting time }\end{array}$ & $412(89.2 \%)$ & $50(10.8 \%)$ & $0(\mathrm{Nil})$ & \\
\hline 6. & $\begin{array}{l}\text { Hygiene and } \\
\text { comfort in } \\
\text { examination } \\
\text { room }\end{array}$ & $408(88.3 \%)$ & $54(11.7 \%)$ & $0(\mathrm{Nil})$ & \\
\hline Total=N (\%) & & & $\begin{array}{c}\mathbf{4 6 2} \\
\mathbf{( 1 0 0 \% )}\end{array}$ \\
\hline
\end{tabular}

can also be taken as the proxy measure for the quality of health care. Proximity to the health care facility is an important key factor which influenced patient preference for it ${ }^{5}$. This study is restricted to the views of the users of the health services and it identifies various impediments in the delivery of health care services that may be important to the users of the healthcare services but may appear trivial to healthcare personnel ${ }^{6}$.

Linder-Pelz (1982) suggested the ten constructs or elements that should be used to determine satisfaction which are accessibility or convenience, availability of resources, continuity of care, efficacy or outcomes of care, finances, humanness, information gathering, pleasantness of surroundings and quality or competence. Satisfied patients are more likely to better comply with provider's medical regimens and to cooperate or maintain a relationship with the specific providers. Learning from these concepts we know that satisfaction plays an important role in quality measure and improvement?

The average waiting time in our study was 116 minutes which was much higher than recorded in earlier studies ${ }^{2,6}$ where it was found to be 30 minutes and that was the main reason for dissatisfaction and non-utilization of services. Even in our study $30 \%$ of the dissatisfaction was due to long waiting time. May be as all the centers were tertiary care 
centers $71 \%$ of the people accept the waiting time to be long. Adequacy in the facilities always had been a major concern for satisfaction as in earlier studies ${ }^{2,4,6,7,9 .}$ Similar to earlier studies, the present study showed only $60 \%$ of satisfaction with the facilities available for ones problem and also only $70 \%$ were happy with the laboratory procedures they availed during their visit.

Every other patient wants to return to the same provider whom they have seen and consulted in their first visit in their follow-up visits too and every client feels satisfied with their follow-up's with the same health provider but unfortunately in our study most of our clients were unsatisfied with their follow-up visits as they could not meet the same provider, about $55 \%$ couldn't meet the first met provider and also $45 \%$ of them felt they did not receive the same care as per their first visit. Most of the time the first visits are without any expectation but later visits will have some expectation as the patient had been to the health care already and it is necessary for the provider and health care facility to satisfy these expectations or else the client satisfaction level goes down.

The privacy and confidentiality satisfaction in clients was found to be very high. This was also an issue of client satisfaction in earlier studies ${ }^{8,9}$ but our study differs from earlier studies. In our study the skills of the provider was also considered high, $30 \%$ of the clients had dissatisfaction of cost in treatment, time given by the

\section{References}

1. M.V.Rao, Dayakar Thota,P.Srinivas.A. A Study of Patient satisfaction in a Tertiary care Teaching Hospital. IOSR Journal of Dental and M edical Sciences, 2014;13(5): Ver. II ,4.

2. Rashmi and Vijaykumar B. Client Satisfaction in Rural India for Primary Health Care - A Tool for Quality Assessment. Al Ameen J Med. Sci, 2010;3(2):109-114.

3. Amrit Virk, Meenu Kalia, BP Gupta and Jasdeep Singh. A Study to evaluate Patient expectation and satisfaction in a tertiary care teaching Hospital. healthline pISSN 2239-337X337X/eISSN 2320-1525 ,2013;4 (2):64.

4. Fekadu Assefa, Andualem Mosse,Yohannes Hailemichael .Assessment of Client's Satisfaction with Health Service Deliveries at Jimma University Specialized Hospital. Ethiop J Health Sci 2011 ; 21(2): 101-109.

5. N Rasheed,S Arya, A Acharya ,J.Khandekar.Client satisfaction and perceptions about quality of health care at a Primary health centre of health care provider to the individual and the information given to them about their problems. But an important issue was $40 \%$ of the clients were unhappy with availability of all services pertaining to their problem which should not have been an issue in a teaching institution. As teaching institutions are considered the tertiary care centers and it is also necessary to have all the facilities which the clients prefer in the Private hospitals. But it is surprising that in our study the satisfaction in availability of all the facilities is poor according to the clients which are of a major concern.

\section{Conclusion}

Our study again revealed that waiting time was of major concern of client satisfaction. Our study also revealed that follow-up visit needs to be given importance to get a better satisfaction. Though the health provider's skills, attitude and the area around for health care were better in satisfaction; but the laboratory services, information about the illness, time given to the patient, availability of all facility for one's problem and cost were of concern for Client satisfaction. One of the limitations of the study is that only private teaching institutions were included and government hospitals were not studied due to the feasibility and time constraints.

Delhi, India .Indian Journal of Community Health ,2012;24(3):241

6. Binod Kumar Patro, Rakesh Kumar, Anil Goswami and Baridalyne Nongkynrih et al. Community Perception and Client Satisfaction about the Primary Health Care Services in an Urban Resettlement Colony of New Delhi. Indian J Community M ed ,2008; 33(4): 250-254.

7. Patrick A. Rivers and Saundra H. Glover .Health care competition, strategic mission, and patient satisfaction, research model and propositions.J Health Organ M anag, 2008; 22(6): 627-641.

8. Zewdie Birhanu, Tsion Assefa, Mirkuzie Woldie, and Sudhakar Morankar .Determinants of satisfaction with health care provider interactions at health centres in central Ethiopia: a cross sectional study.BM CHealth Serv Res, 2010; 10: 78.

9. Salih A. Binsalih, Abdelkarim O. Waness, Hani M. Tamim, M ohamed S Harakati, and Abdulla A. Al Sayyari .Inpatients' care experience and satisfaction study. J Family Community M ed , 2011 ; 18(3): 111-117. 